\section{Quando a Linguística Aplicada e a Psicologia Cognitiva auxiliam a Lexicografia: ilustrações em dicionários infantis}

When Applied Linguistics and Cognitive Psychology cooperate with Lexicography: illustrations in children's dictionaries

Laura Campos de BORBA (UFRGS) lauracborba@hotmail.com

Recebido em: 13 de ago. de 2020. Aceito em: 28 de ago. de 2020.
BORBA, Laura Campos de. Quando a

Linguística Aplicada e a Psicologia

Cognitiva auxiliam a Lexicografia: ilustrações em dicionários infantis. Entrepalavras, Fortaleza, v. 11, n. esp., p. 120-142, ago. 2021. DOI: 10.22168/2237-6321-10esp2025.

Resumo: O objetivo deste trabalho é avaliar a utilidade das ilustrações de três dicionários infantis para crianças do $1^{\mathrm{O}}$ ano do Ensino Fundamental. Foram analisadas as obras selecionadas pelo PNLD Dicionários (BRASIL, 2012): Meu primeiro livro de palavras (MPLP, 2010); Meu primeiro dicionário Caldas Aulete (MPCA, 2009); e Dicionário Infantil Ilustrado Evanildo Bechara (DInf, 2011). O referencial teórico advém da Metalexicografia em relação ao caráter elucidativo das ilustrações e em relação ao usuário do dicionário (FARIAS, 2013); da Linguística Aplicada no tocante às dificuldades específicas de crianças em fase de alfabetização (CAGLIARI, 2003; PESSOA; MORAIS, 2010); e da Psicologia Cognitiva em relação a dados de familiaridade entre crianças brasileiras (POMPÉIA et al., 2001). A metodologia consistiu, primeiramente, na verificação da inclusão de referentes familiares com representação ortográfica difícil para alfabetizandos nos dicionários e na averiguação da presença de ilustrações. Em seguida, avaliou-se o grau de elucidação das ilustrações encontradas. Os resultados revelam que a proporção de casos com ilustrações não elucidativas e/ou sem ilustrações é igual ou superior 
aos casos com ilustrações elucidativas. Conclui-se que a falta de embasamento das ilustrações em relação às necessidades linguísticas do usuário é o principal problema dos dicionários avaliados.

Palavras-chave: Dicionários infantis. Perfil de usuário de dicionário. Ilustrações.

\begin{abstract}
This paper evaluated the usefulness of illustrations in three children's dictionaries for Brazilian children developing literacy. Three dictionaries from PNLD Dicionários (BRASIL, 2012) were analysed: Meu primeiro livro de palavras (MPLP, 2010); Meu primeiro dicionário Caldas Aulete (MPCA, 2009); and Dicionário Infantil Ilustrado Evanildo Bechara (DInf, 2011). The theoretical basis of the paper comes from the concepts of elucidation and the dictionary's user profile in Metalexicography (FARIAS, 2013); Applied Linguistics, specifically difficulties children experience when developing literacy (CAGLIARI, 2003; PESSOA; MORAIS, 2010); and Cognitive Psychology, precisely data of familiarity among Brazilian children (POMPÉIA et al., 2001). First, I analysed which familiar and orthographically difficult referents were included and if there were illustrations. Then, I evaluated the degree of elucidation in each illustration found. Results reveal that there are as many cases with elucidative illustrations as cases with non-elucidative illustrations and cases without illustration when this resource would help the user. The main problem of illustrations from all the three dictionaries analysed was the lack of inclusion criteria based on the user's needs.
\end{abstract}

Keywords: Children's dictionaries. Dictionary user profile. Illustrations.

\title{
Introdução
}

Cada vez mais, a literatura em Lexicografia reforça que é necessário lançar um olhar mais atento ao usuário pretenso por uma obra lexicográfica, pois nisso se encontra o futuro da área (BOGAARDS, 2003, p. 26; RUNDELL, 2008, p. 230; NESI, 2013, p. 1; BORBA; BUGUEÑO MIRANDA, 2019, p. 1026-1028). Quanto mais precisa for a definição do perfil de usuário que um dicionário almeja alcançar, melhor será a resposta da própria obra no que tange às necessidades do seu consulente ${ }^{1}$. Definir esse perfil é essencial para a tomada de decisões sobre que informações incluir e que recursos serão empregados para descrevê-las, sejam metalinguísticos, como a paráfrase explanatória, sejam não linguísticos, como as ilustrações.

Segundo Bugueño Miranda (2019, p. 33), os dicionários compilados para auxiliar no ensino-aprendizagem de línguas são os que oferecem mais pistas sobre como definir o usuário, tendo em vista que as suas necessidades abarcam o componente curricular. Além disso, igualmente úteis são os trabalhos que discorrem sobre as necessidades específicas de grupos de alunos com uma determinada característica em comum, como mesma etapa de aprendizagem e mesma língua materna, no caso dos dicionários de aprendizes.

\footnotetext{
${ }^{1}$ Consulente e usuário são vistos neste artigo como sinônimos.
} 
V. 11 (esp.)

$120-142$ ago. 2021

A classe de obras que interessa tratar nesta oportunidade são os dicionários escolares, mais precisamente o subgrupo dos dicionários infantis Tipo 1 - isto é, obras compiladas para auxiliar crianças que se encontram no primeiro ano do Ensino Fundamental da Educação Básica brasileira. No Brasil, há três expoentes de dicionários infantis Tipo 1, destacados pela sua recomendação no Programa Nacional do Livro Didático - Dicionários (BRASIL, 2012) e, posteriormente, no Programa Nacional Biblioteca na Escola 2013 (BRASIL, 2013): Meu primeiro livro de palavras (MPLP, 2010); Meu primeiro dicionário Caldas Aulete com a Turma do Cocoricó (MPCA, 2009); e Dicionário Infantil Ilustrado Evanildo Bechara (DInf, 2011). Em geral, essa classe de dicionários apresenta três segmentos informativos recorrentes: lema, paráfrase explanatória e ilustração. Dentre eles, o segmento informativo que menos conta com orientações metalexicográficas que orientam a sua inclusão são as ilustrações (FARIAS, 2013, p. 300). Avaliar as ilustrações nos dicionários supracitados adquire uma relevância fundamental por duas razões. A primeira delas é que esse tipo de mecanismo explanatório está presente em 10.4\% ( $\mathrm{n}=236)$ do total de verbetes do MPLP (2010), 55\% ( $\mathrm{n}=748)$ do total de verbetes do MPCA (2009) e em 35,7\% ( $n=357)$ do total de verbetes do DInf (2011) ${ }^{2}$. A segunda razão é dada pelo próprio PNLD Dicionários, à medida que determina a obrigatoriedade de se incluir ilustrações em dicionários escolares Tipo 1 (BRASIL, 2012, p. 95), tais como as três obras citadas.

O objetivo deste artigo é avaliar a utilidade das ilustrações do MPLP (2010), do MPCA (2009) e do DInf (2011) para o seu usuário pretenso, isto é, crianças cursando o primeiro ano do Ensino Fundamental. O marco teórico que fundamenta a análise consiste, por um lado, na análise das orientações do PNLD Dicionários (BRASIL, 2012) e da Base Nacional Comum Curricular / BNCC (BRASIL, 2018). Por outro lado, além deste documento, são empregados subsídios de três áreas. Em primeiro lugar, a Metalexicografia, em relação ao usuário (ANTONIOLI, 2012) e às ilustrações (FARIAS, 2013). Em segundo lugar, a Linguística Aplicada ao ensino-aprendizagem de línguas, mais especificamente as dificuldades específicas de crianças em fase de alfabetização3 (CAGLIARI,

${ }^{2}$ Dentre os três dicionários, foram contabilizadas somente as ilustrações inseridas nos verbetes da nominata. Não foram considerados os quadros ilustrativos do back matter das obras.

${ }^{3}$ Emprega-se o termo alfabetização, primeiramente, porque é o termo usado nos documentos oficiais do Ministério da Educação (BRASIL, 2012, 2018). Em segundo lugar, Antonioli (2012, p. $39-45$; 57) defende o uso do termo para referir-se ao $1^{\circ}$ e $2^{\circ}$ anos do Ensino Fundamental. Segundo a autora, alfabetização faz alusão ao processo individual que implica a codificação da escrita, e não tanto à dimensão social, à qual se refere o termo letramento. 
2003; PESSOA; MORAIS, 2010). Em terceiro lugar, a Psicologia Cognitiva, por meio de estudos sobre o conceito de familiaridade (YONELINAS, 2002; POMPÉIA et al., 2001). Como este artigo decorre diretamente de um trabalho anterior, no qual se discute largamente o marco teórico adotado, a apresentação que se faz é mais sucinta, porém, necessária para esclarecer as bases que fundamentam a ferramenta usada para analisar os dicionários. Em seguida, procede-se à análise.

\section{Dicionários infantis Tipo 1 e ilustrações}

O Programa Nacional do Livro Didático (PNLD) 2012 - Dicionários (BRASIL, 2012), classifica os dicionários direcionados à Educação Básica em quatro tipos. O Tipo 1 está direcionado a alunos do $1^{0}$ ano do Ensino Fundamental (doravante EF). Conforme o documento, enquadram-se nesse tipo aquelas obras que possuam entre 500 e 1000 verbetes e cujo conteúdo "esteja adequado às demandas do processo de alfabetização inicial" (BRASIL, 2012, p. 19). Em relação ao número de verbetes, curiosamente, o MPLP (2010) e o MPCA (2009) acabam ultrapassando o intervalo estipulado em Brasil (2012), muito embora Farias (2013) comente que "a elasticidade na definição do volume da nomenclatura dos dicionários parece atender ao propósito de 'acomodar' aos critérios de avaliação [do PNLD] os dicionários disponibilizados pelo mercado editorial brasileiro [...]" (FARIAS, 2013, p. 306).

A respeito da função dos dicionários Tipo 1, o PNLD Dicionários destaca que a "compreensão e aquisição da escrita" (BRASIL, 2012, p. 22) seriam funções próprias da etapa de ensino em questão a serem cumpridas pelos dicionários Tipo 1. A partir desses critérios, o MPLP (2010), o MPCA (2009) e o DInf (2011) foram selecionados como expoentes de dicionário escolar Tipo 1 e distribuídos nas escolas públicas brasileiras.

O PNLD - Dicionários (BRASIL, 2012) aponta ainda uma série de características específicas relativas aos dicionários de Tipo 1:

- recolhem, em sua nomenclatura, um número limitado de verbetes, incapaz de refletir a variedade dos tipos de palavras e expressões que o léxico de uma língua como o português brasileiro abriga;

- têm como foco o vocabulário que seus autores consideram básico;

- propiciam ao trabalho de sala de aula um primeiro acesso ao universo das palavras e dos dicionários;

- recorrem a ilustrações como estratégia tanto de motivação da leitura (ilustrações ficcionais) quanto de explicitação de 
v. 11 (esp.)

$120-142$

ago.

2021 sentidos das palavras (funcionais);

- trazem verbetes de estrutura simples, com um pequeno número de acepções e informações linguístico-gramaticais reduzidas ao indispensável - quase sempre em linguagem informal e acessível, acompanhada de exemplos de uso (BRASIL, 2012, p. 22).

O primeiro e o segundo itens correspondem ao que, na teoria metalexicográfica, considera-se como diassistemicamente restritivo (isto é, almeja-se apenas parte do léxico de uma língua) e que envolve a seleção macroestrutural. Cabe questionar quais foram os critérios teórico-metodológicos empregados pelos autores dos dicionários para seleção e inclusão de unidades léxicas e no que consiste um vocabulário básico, já que, ao menos numericamente, os três dicionários variam consideravelmente entre si sem que se possa compreender o porquê.

O terceiro item diz respeito a um dos objetivos do PNLD Dicionários, que é incentivar o uso do dicionário em sala de aula.

O quarto item revela a função das ilustrações nos dicionários, qual seja, atrair a atenção do usuário e auxiliá-lo a compreender o sentido das unidades léxicas. De fato, a teoria lexicográfica tem atribuído cada vez mais atenção às ilustrações por meio dos estudos no campo da multimodalidade, que se ocupa da relação entre elementos verbais e não verbais e entre elementos não verbais e o consulente (cf. NASCIMENTO, 2018), e da teoria geral dos mecanismos explanatórios de Farias (2013), por exemplo. No Brasil, a atenção recai em especial sobre as ilustrações em dicionários escolares, como se verifica em Nascimento (2018), Pontes (2010a,b; 2018), Santos (2018) e Santos, Coriolano e Pontes (2019) para citar alguns trabalhos.

De acordo com Farias (2013, p. 288), a principal razão para justificar a inclusão de ilustrações em uma obra lexicográfica deveria ser o potencial de auxílio daquelas na compreensão de informações do verbete. Entretanto, Klotz e Herbst (2016, p. 66) reconhecem que o propósito das ilustrações nos dicionários em geral "[...] parece ser mais estético: elas melhoram a aparência geral de um dicionário e transformam-no em um produto mais 'amigável' "4.

Para que se possa determinar quando é pertinente incluir uma ilustração, é necessário esclarecer em que situações o usuário pretenso (no caso, crianças em fase de alfabetização) apresentará dificuldades na compreensão de informações no verbete. É pertinente observar que nem o

4 [rather seems to be an aesthetic one: they improve the general appearance of a dictionary and turn it into a more "friendly" product]. 
PNLD Dicionários (BRASIL, 2012) nem os dicionários Tipo 1 selecionados esclarecem essa questão. Há que considerar que o estabelecimento de uma relação entre as necessidades do usuário e a função das ilustrações nos dicionários é um tema incipiente na Metalexicografia; em função disso, tanto os documentos oficiais como os dicionários escolares disponíveis não puderam contar com os avanços recentes dessa reflexão.

Para este artigo, o referencial teórico que lança mais luz sobre os critérios de inclusão de ilustrações em dicionários é o que propõe Farias (2013, p. 285-301). A autora, por um lado, estabelece que tipos de unidades léxicas normalmente se apresentam com paráfrases explanatórias difíceis de compreender e, por outro lado, esclarece em que consiste a elucidação de um significado. No que tange às paráfrases explanatórias difíceis de compreender, Farias (2013, p. 285288) comenta que há determinados tipos de unidades léxicas que são naturalmente mais complicadas para se definir, tais como as classes naturais e as palavras gramaticais. Nestes casos, segundo Farias (2013, p. 285), mesmo com o subsídio de teorias semânticas, as paráfrases explanatórias geradas terminam sendo opacas, isto é, não expressam um significado de maneira clara. Como solução, a autora propõe que, dentre os mecanismos explanatórios complementares existentes, as ilustrações sejam empregadas na elucidação de nomes que designam classes naturais, artefatos e realia (unidades léxicas próprias de uma cultura).

A elucidação de um significado, por sua vez, depende da classe de obras em questão, do perfil de usuário e de propriedades específicas que tornam elucidativa uma ilustração (FARIAS, 2013, p. 300). Primeiramente, no que concerne à classe de obras, o dicionário escolar Tipo 1, também denominado dicionário infantil Tipo 1 nesta oportunidade, é uma obra que reflete um vocabulário considerado básico, com um número reduzido de acepções e informações linguístico-gramaticais e que deve apresentar obrigatoriamente dois segmentos informativos: definições $^{5}$ e ilustrações (BRASIL, 2012, p. 95). Em segundo lugar, o perfil de usuário são crianças em fase de alfabetização (cf. mais detalhes na próxima seção). Em terceiro lugar, as propriedades que

\footnotetext{
${ }^{5}$ Usa-se no trecho em questão o termo mencionado pelo PNLD Dicionários (BRASIL, 2012, p. 95), embora prefira-se empregar na presente argumentação o termo paráfrase explanatória. A razão para essa escolha reside no fato de que o conceito de definição abarca somente a fórmula aristotélica de gênero próximo e diferença específica (BUGUEÑO MIRANDA, 2009, p. 243-244); além disso, segundo Creese et al. (2018, p. 5), definição implica fornecer todas as características de um referente, o que é impossível.
} 
v. 11 (esp.)

$120-142$ ago. 2021

tornam uma ilustração elucidativa são, segundo Farias (2013, p. 301): a) a possibilidade de se estabelecer uma relação direta com o referente; b) a sua boa qualidade; e c) um sistema de remissões que facilite a localização de ilustrações, especialmente quando elas não estão junto do verbete, mas em outro verbete ou componente canônico do dicionário (back matter, isto é, as páginas que seguem após a nominata). Destas três particularidades, a conexão direta com o referente é a principal e será considerada nas análises dos dicionários.

Como se depreende do exposto até aqui, a Metalexicografia é orientada por critérios que permitem avaliar o âmbito da pertinência das ilustrações e do seu caráter elucidativo em um dicionário. Entretanto, as necessidades específicas de cada grupo de usuários só podem ser estabelecidas a partir de estudos de outras áreas, mais precisamente da Linguística Aplicada e da Psicologia Cognitiva. Os aportes de ambas para a definição das necessidades do usuário de dicionários infantis Tipo 1 serão contemplados nas próximas duas seções.

\section{Perfil de usuário: crianças brasileiras em fase de alfabetização}

A determinação de um perfil de usuário é necessária para que toda metodologia de descrição lexicográfica de uma língua tenha uma fundamentação clara. No caso dos dicionários infantis Tipo 1, é preciso comparar as informações que constam nos próprios dicionários e no PNLD Dicionários (BRASIL, 2012) com as orientações que constam na BNCC (BRASIL, 2018) e com as contribuições da Linguística Aplicada (ANTONIOLI, 2012; CAGLIARI, 2003; PESSOA; MORAIS, 2010) e da Psicologia Cognitiva (POMPÉIA et al., 2001).

Conforme já mencionado anteriormente, entre as informações que o PNLD Dicionários (BRASIL, 2012, p. 22; 95) recomenda, estão as definições, um número reduzido de acepções, informações linguísticogramaticais consideradas indispensáveis (sem determinar quais são), exemplos de uso e ilustrações. Tais recomendações resultaram em diferentes segmentos informativos incluídos nos verbetes dos dicionários analisados. As informações do comentário de forma (i.e. informações sobre uma unidade léxica enquanto significante) e do comentário semântico (i.e. informações sobre uma unidade léxica na dimensão do significado) dos dicionários analisados estão reunidas no Quadro 1: 
Quadro 1 - Informações dos verbetes do MPLP (2010), do MPCA (2009) e do DInf (2011)

\begin{tabular}{|l|l|l|l|}
\hline \multicolumn{1}{|c|}{ Comentário de forma } & \multicolumn{1}{|c|}{ MPLP (2010) } & \multicolumn{1}{|c|}{ MPCA (2009) } & \multicolumn{1}{c|}{ Inf (2011) } \\
\hline representação ortográfica & $\operatorname{sim}$ & & \\
\hline separação silábica & $\operatorname{sim}$ & $\operatorname{sim}$ & $\operatorname{sim}$ \\
\hline sílaba tônica & $\operatorname{sim}$ & $\operatorname{sim}$ & $\operatorname{sim}$ \\
\hline \multicolumn{1}{|c|}{ Comentário semântico } & & não & $\operatorname{sim}$ \\
\hline paráfrase explanatória & 1 a 3 & 1 a 3 & \\
\hline exemplo & $\operatorname{sim}$, sempre & esporádicos & esporádicos \\
\hline sinônimos e antônimos & $\operatorname{sim}$ & antônimos & sim \\
\hline famílias de palavras & $\operatorname{sim}$ & não & sim \\
\hline
\end{tabular}

Fonte: elaboração da autora (2021) com base nos dados do MPLP (2010), do MPCA (2009) e do DInf (2011).

Os compiladores das obras presumem que a criança em fase de alfabetização poderá compreender esse leque de informações e tirar proveito delas para resolver suas dúvidas. Contudo, tal variedade de informações não é inteiramente convergente com as orientações que constam na atual BNCC (BRASIL, 2018, p. 89-93) sobre alfabetização nem com os critérios de avaliação da Provinha Brasil, que já era aplicada à época da publicação das referidas obras (ANTONIOLI, 2012, p. 49).

A BNCC (BRASIL, 2018) salienta que, no $1^{\circ}$ e $2^{\circ}$ anos do Ensino Fundamental, ocorre o processo de alfabetização, que, conforme o documento, "deve ser o foco da ação pedagógica" (BRASIL, 2018, p. 89). A BNCC (BRASIL, 2018) ainda especifica que ser alfabetizado consiste em saber:

\footnotetext{
"codificar e decodificar" os sons da língua, (fonemas) em material gráfico (grafemas ou letras), o que envolve o desenvolvimento de uma consciência fonológica (dos fonemas do português do Brasil e de sua organização em segmentos sonoros maiores como sílabas e palavras) e o conhecimento do alfabeto do português do Brasil em seus vários formatos (letras imprensa e cursiva, maiúsculas e minúsculas), além do estabelecimento de relações grafofônicas entre esses dois sistemas de materialização da língua (BRASIL, 2018, p. 89-90, aspas no original).
}

Em termos metalexicográficos, a ênfase da alfabetização incide sobre o comentário de forma, mais precisamente a ortografia e os conhecimentos necessários para tal (consciência fonológica, alfabeto e relações grafofônicas). Note-se que no apanhado acerca da alfabetização, a BNCC não menciona a dimensão do significado (BRASIL, p. 89-93). 
v. 11 (esp.)

$120-142$ ago. 2021

Isso significa que o consulente a quem se dirigem o MPLP (2010), o MPCA (2009) e o DInf (2011) não poderá aproveitar as informações do comentário semântico que as obras incluem simplesmente porque ainda não é capaz de compreendê-las e porque seu aprendizado não integra o escopo do $1^{\mathrm{O}}$ ano do Ensino Fundamental.

Há alguns anos, Antonioli (2012, p. 49) já apontava os problemas da inclusão da dimensão do significado em dicionários infantis com base nos critérios de avaliação da Provinha Brasil e em Ferreiro (2002 apud Antonioli, 2012, p. 49) acerca das fases de desenvolvimento fonológico ambos convergentes com as atuais orientações da BNCC (BRASIL, 2018).

Tendo em vista os tipos de segmentos informativos relevantes a um alfabetizando, é necessário reconsiderar os tipos de dúvidas que levarão o usuário ao dicionário e como as ilustrações, enquanto mecanismos explanatórios complementares, podem ser usadas para auxiliar na compreensão das representações ortográficas - ao menos daquelas que oferecem maiores dificuldades.

Na Linguística Aplicada, as pesquisas sobre os contextos ortográficos que podem causar dificuldades em crianças em fase de alfabetização são de extrema valia para que se determinem quais unidades léxicas precisariam obrigatoriamente de uma ilustração. Nesse sentido, os dados presentes em Cagliari (2003) e Pessoa e Morais (2010) acerca da formulação de hipóteses ortográficas por alfabetizandos permite que se determine com maior clareza que contextos ortográficos precisam de especial atenção ao se compilar um dicionário infantil Tipo 1. O Quadro 2 reúne os dados dos autores supracitados:

Quadro 2 - Contextos ortográficos complexos para alfabetizandos

\begin{tabular}{|l|l|}
\hline \multicolumn{1}{|c|}{ Contexto ortográfico } & \multicolumn{1}{|c|}{ Exemplos de Cagliari (2003) } \\
\hline Neutralização da vogal átona: $e \rightarrow i, o \rightarrow u$ & $*$ qui (que); *tudu (tudo) \\
\hline Ditongação da tônica final: $a \rightarrow a i, e \rightarrow e i$ & *rapais (rapaz); *feis (fez) \\
\hline $\begin{array}{l}\text { Monotongação de sílabas átonas: ei } \rightarrow e, \\
\text { ou } \rightarrow \text { o }\end{array}$ & pergunto (perguntou) \\
\hline Apagamento do $r$ em final de palavra & *mulhe (mulher); lava (lavar) \\
\hline Apagamento do s em final de palavra & *vamu (vamos) \\
\hline Uso de $u$ em lugar de l em final de sílaba & sou (sol), *sauva (salvar) \\
\hline Uso de li em lugar do dígrafo lh & *coelio (coelho) \\
\hline $\begin{array}{l}\text { Fonema /s/ e suas representações em } x \text { e } \\
\text { ch }\end{array}$ & *xata (chata), *licho (lixo) \\
\hline $\begin{array}{l}\text { Fonema /s/ e suas representações em } s, z, \\
\text { c, ç e ss }\end{array}$ & $\begin{array}{l}\text { *susego (sossego), *felis (feliz), *aseito } \\
\text { (aceito) }\end{array}$ \\
\hline
\end{tabular}




\begin{tabular}{|l|l|}
\hline \multicolumn{1}{|c|}{ Contexto ortográfico } & Exemplos de Pessoa e Morais (2010) \\
\hline $\begin{array}{l}\text { Fonema /3/ e suas representações em j e } \\
g\end{array}$ & gente, janela \\
\hline Nasalização através de $m, n, n h$ ou & mãe, caminhão, pente \\
\hline $\begin{array}{l}\text { Fonema /x/ e suas representações em } r \text { e } \\
\text { rr }\end{array}$ & relógio, cachorro \\
\hline $\begin{array}{l}\text { Fonema /x/ e suas representações em } z, \\
\text { s, } x\end{array}$ & casa, exemplo \\
\hline $\begin{array}{l}\text { Fonte: elaboração da autora a partir de dados de Cagliari (2003) e Pessoa e Morais } \\
(2010) .\end{array}$
\end{tabular}

O mecanismo de localização de informações usado pelo dicionário infantil Tipo 1, isto é, a progressão alfabética, já constitui, per se, um desafio para o consulente em fase de alfabetização, especialmente tendo em vista os contextos ortográficos reunidos no Quadro 2. As ilustrações, por sua vez, podem funcionar como um sistema paralelo que auxilia o consulente a localizar mais rapidamente a informação que procura. Há, noentanto, umaspectoa serconsiderado:ailustraçãosomente será útil quando se referir a entidades extralinguísticas já conhecidas pela criança, que permitam que ela empregue seu conhecimento prévio. Embora seja uma informação subjetiva, a Psicolinguística fornece dados que lançam luz sobre a questão. Trata-se de um tipo de pesquisa que mede a familiaridade de grupos populacionais em relação a determinados referentes extralinguísticos comumente usados em investigações da área. O conceito de familiaridade diz respeito ao conhecimento de mundo dos indivíduos, ao que se tem ciência sem que necessariamente se possa identificar quando tal informação foi armazenada na memória (YONELINAS, 2002). Se um determinado referente como cupuaçu não for familiar à criança, uma ilustração não acarretará uma facilitação na compreensão da representação ortográfica desse referente.

No Brasil, o estudo de Pompéia, Miranda e Bueno (2001) é pioneiro - e, até o momento, o único - no estabelecimento dos referentes extralinguísticos mais familiares para crianças brasileiras entre cinco e sete anos de idade, ou seja, em uma etapa que abarca o período da alfabetização. Os autores usaram um conjunto padrão empregado internacionalmente composto por 400 ilustrações como estímulo para medir a familiaridade de 36 crianças brasileiras da faixa etária supracitada. O grau de familiaridade foi medido por meio de uma escala de três níveis, que acarretava pontuações diferentes: muito (5 pontos), algumas vezes (3 pontos) e muito pouco (1 ponto). Ao final, 
v. 11 (esp.)

$120-142$ ago. 2021

computou-se a média de pontos e o desvio padrão para a familiaridade de cada ilustração. A designação mais empregada pelas crianças para cada ilustração também foi computada pelos pesquisadores.

A partir da correlação entre dificuldades ortográficas e referentes com maior grau de familiaridade para crianças brasileiras, em Borba (2018) propõe-se uma ferramenta de avaliação de ilustrações de dicionários infantis Tipo 1 que levasse em conta as necessidades desse perfil de usuário no que tange aos contextos ortográficos que lhes oferecem maior dificuldade e aos referentes mais familiares para esse público. Uma versão revisada da ferramenta está reproduzida no Anexo 1 e foi usada para avaliar as ilustrações do MPLP (2010), do MPCA (2009) e do DInf (2011). Os resultados são apresentados na seção a seguir.

\section{Análise dos dicionários infantis Tipo 1}

A metodologia de análise consistiu na aplicação de uma versão revisada da ferramenta proposta em Borba (2018) (cf. Anexo 1). Nela constam 79 referentes mais familiares a crianças brasileiras entre cinco e sete anos cuja representação ortográfica pode causar dificuldades em alfabetizandos. Primeiramente, verificou-se quais dos 79 referentes apontados na ferramenta estavam incluídos nos dicionários. Nessa etapa, averiguou-se também onde e como estavam registrados tais referentes, isto é, se na macroestrutura, sob a forma de palavra-entrada, e/ou no back matter, em diagramas ou em listas. Em segundo lugar, dentre os referentes incluídos em cada obra, assinalou-se quais contavam com ilustrações. Finalmente, e à luz de Farias (2013, p. 301), as ilustrações encontradas foram classificadas em relação ao seu poder elucidativo como elucidativas e não elucidativas.

Análise do MPLP (2010)

O Quadro 3 contém os resultados da análise do MPLP (2010): 
Quadro 3 - Análise de referentes e ilustrações no MPLP (2010)

\begin{tabular}{|c|c|c|c|}
\hline \multirow{2}{*}{$\begin{array}{c}\text { Inclusão do referente no } \\
\text { dicionário }\end{array}$} & \multicolumn{3}{|c|}{ Localização do referente (e da ilustração) } \\
\hline & Macroestrutura & Back matter & $\begin{array}{c}\text { Macroestrutura e } \\
\text { back matter }\end{array}$ \\
\hline $\begin{array}{l}\text { Referente incluído e } \\
\text { ilustrado no dicionário. } \\
\text { A ilustração é } \\
\text { elucidativa. } \\
27 / 79(34,17 \%)\end{array}$ & $\begin{array}{l}\text { árvore } \\
\text { caminhão } \\
\text { casa } \\
\text { lâmpada } \\
\text { ônibus } \\
\text { xícara }\end{array}$ & $\begin{array}{l}\text { abelha (p.230) } \\
\text { bolsa (p.223) } \\
\text { boné (p.223) } \\
\text { braço (p.222) } \\
\text { cabide (p.222) } \\
\text { cadeira (p.222) } \\
\text { calça (p.222) } \\
\text { cama (p.222) } \\
\text { dedo (p.222) } \\
\text { escova (p.222) } \\
\text { garrafa (p.222) } \\
\text { gato (p.231) } \\
\text { guarda-roupa } \\
\text { (p.223) } \\
\text { mão (p.222) } \\
\text { nariz (p.222) } \\
\text { óculos (p.222) } \\
\text { olho (p.222) }\end{array}$ & $\begin{array}{l}\text { banana (p.228) } \\
\text { orelha (p.222) } \\
\text { relógio (p.222) } \\
\text { vaso (p.222) }\end{array}$ \\
\hline $\begin{array}{c}\text { Referente incluído e } \\
\text { ilustrado no dicionário. } \\
\begin{array}{c}\text { A ilustração não é } \\
\text { elucidativa. } \\
4 / 79(5 \%)\end{array}\end{array}$ & --- & $\begin{array}{l}\text { bicicleta (p.222) } \\
\text { pente (p.222) }\end{array}$ & $\begin{array}{l}\text { livro (p.222) } \\
\text { telefone (p.222) }\end{array}$ \\
\hline $\begin{array}{l}\text { Referente incluído sem } \\
\text { ilustração no dicionário. } \\
\qquad 31 / 79(39,2 \%)\end{array}$ & $\begin{array}{l}\text { banco } \\
\text { botão } \\
\text { carro } \\
\text { colher } \\
\text { flor } \\
\text { pão } \\
\text { pássaro } \\
\text { pneu } \\
\text { quadro } \\
\text { sol }\end{array}$ & $\begin{array}{l}\text { abajur (p.223) } \\
\text { agulha (p.223) } \\
\text { anel (p.223) } \\
\text { cachorro (p.231) } \\
\text { caneta (p.223) } \\
\text { chapéu (p.223) } \\
\text { chave (p.223) } \\
\text { chuveiro (p.223) } \\
\text { cinto (p.223) } \\
\text { escada (p.223) } \\
\text { formiga (p.230) } \\
\text { geladeira (p.223) } \\
\text { maçã (p.229) } \\
\text { martelo (p.223) } \\
\text { pote (p.223) } \\
\text { sanduíche (227) } \\
\text { sapato (p.223) } \\
\text { tesoura (p.223) } \\
\text { tomate (p.226) } \\
\text { vassoura (p.223) } \\
\text { vestido (p.223) }\end{array}$ & --- \\
\hline $\begin{array}{c}\text { Referente ausente do } \\
\text { dicionário } \\
16 / 79(20,2 \%)\end{array}$ & $\begin{array}{l}\text { batom } \\
\text { blusa } \\
\text { cadeado } \\
\text { colete } \\
\text { copo } \\
\text { escova de dente }\end{array}$ & $\begin{array}{l}\text { estrela } \\
\text { ferro } \\
\text { fogão } \\
\text { garfo } \\
\text { guarda-chuva }\end{array}$ & $\begin{array}{l}\text { janela } \\
\text { mesa } \\
\text { panela } \\
\text { pregador } \\
\text { roda-gigante }\end{array}$ \\
\hline
\end{tabular}


v. 11 (esp.)

$120-142$ ago. 2021

O primeiro dado que chama a atenção é o fato de que grande parte dos referentes analisados se encontra registrada somente no back matter do MPLP (2010). No Quadro 3, a coluna Back matter abriga 40 dos 79 referentes $(50,6 \%)$, enquanto $16(20,2 \%)$ dos referentes estão presentes na macroestrutura. É pertinente salientar que a alta familiaridade das crianças brasileiras com os 79 referentes em questão pressupõe uma necessidade mais imediata de tirar dúvidas sobre a representação ortográfica desses referentes. Em função disso, fica claro que o alfabetizando poderá tirar muito mais proveito da consulta ao back matter em comparação com a macroestrutura, pois lá estarão registrados os referentes que mais lhe interessam nessa fase de aprendizagem. É curioso que o conteúdo mais relevante para o consulente esteja disposto somente no último componente do dicionário. Também vale retomar o questionamento acerca do tipo de unidades léxicas que receberam o privilégio de constar na macroestrutura, isto é, um componente muito mais relevante para a obra lexicográfica que o back matter. Em se tratando de alfabetizandos, a consulta à obra torna-se muito mais dispendiosa, pois, muitas vezes, haverá um caminho longo a se percorrer até chegar à representação ortográfica desejada.

O segundo dado a chamar a atenção é que apenas $1 / 3$ do total de referentes analisados conta com uma ilustração que auxilia na identificação do referente (primeiro descritor do Quadro 3). Esse dado já demonstra a ausência de critérios de inclusão de ilustrações que levem em conta as necessidades do perfil de usuário da obra.

Dentre as ilustrações classificadas como elucidativas, apenas uma pequena parcela acompanha os verbetes correspondentes; as demais se encontram no back matter da obra. Há ainda casos de referentes que estão incluídos tanto na macroestrutura, sob a forma de verbetes não ilustrados, como no back matter, com ilustração (cf. banana - vaso, apresentados no Quadro 3). Surpreende que não haja uma remissão do verbete na macroestrutura para a página do back matter onde se encontra a respectiva ilustração.

Ainda no tocante às ilustrações elucidativas, é preciso considerar que muitas delas estão dispostas de maneira desorganizada no back matter da obra. Nas páginas 222 e 223 ("Você e as coisas"), há um diagrama que almeja representar o quarto de uma criança em um estado bagunçado, ou seja, com diversos objetos espalhados desordenadamente pela cama e pelo chão, e que correspondem aos referentes que se deseja descrever. Por mais que a representação individual da maioria dos referentes 
do diagrama seja elucidativa, a desordem com que estão dispostas as ilustrações individuais de cada referente dificulta a sua localização. Além disso, nota-se a intenção de ilustrar o maior número possível de referentes num mesmo cenário, o que termina sobrecarregando-o. Portanto, parte significativa das ilustrações classificadas na primeira categoria do Quadro 3 pode terminar sendo pouco elucidativa tendo em vista a maneira como estão dispostas no cenário.

Finalmente, dentre as ilustrações consideradas não elucidativas, as dos referentes pente e livro ilustram esses objetos de um ângulo que dificulta a sua identificação, enquanto em bicicleta, o referente está desenhado pela metade e atrás de outra ilustração. Já em telefone, o modelo de telefone de disco empregado já não é mais produzido atualmente.

Análise do MPCA (2009)

O Quadro 4 contém os resultados da análise do MPCA (2009):

Quadro 4 - Análise de referentes e ilustrações no MPCA (2009)

\begin{tabular}{|c|c|c|c|}
\hline \multirow{2}{*}{$\begin{array}{c}\text { Inclusão do referente no } \\
\text { dicionário }\end{array}$} & \multicolumn{3}{|c|}{ Localização do referente } \\
\hline & \multicolumn{2}{|c|}{ Macroestrutura } & $\begin{array}{c}\text { Macroestrutura e } \\
\text { back matter }\end{array}$ \\
\hline $\begin{array}{l}\text { Referente incluído e } \\
\text { ilustrado no dicionário. } \\
\text { A ilustração é } \\
\text { elucidativa. } \\
27 / 79(34,1 \%)\end{array}$ & $\begin{array}{l}\text { abelha } \\
\text { agulha } \\
\text { árvore } \\
\text { banana } \\
\text { blusa } \\
\text { cadeira } \\
\text { calça } \\
\text { caminhão } \\
\text { casa } \\
\text { colher } \\
\text { escada } \\
\text { fogão }\end{array}$ & $\begin{array}{l}\text { formiga } \\
\text { garfo } \\
\text { gato } \\
\text { lâmpada } \\
\text { maçã } \\
\text { ônibus } \\
\text { pão } \\
\text { sanduíche } \\
\text { sapato } \\
\text { tesoura } \\
\text { tomate } \\
\text { xícara }\end{array}$ & $\begin{array}{l}\text { braço (p.202) } \\
\text { dedo (p.202) } \\
\text { nariz (p.202) } \\
\text { (mão, p.202) } \\
\text { (olho, p.202) } \\
\text { (orelha, p.202) }\end{array}$ \\
\hline $\begin{array}{c}\text { Referente incluído e } \\
\text { ilustrado no dicionário. } \\
\begin{array}{c}\text { A ilustração não é } \\
\text { elucidativa. } \\
34 / 79(43 \%)\end{array}\end{array}$ & $\begin{array}{l}\text { anel } \\
\text { bicicleta } \\
\text { bolsa } \\
\text { boné } \\
\text { cachorro } \\
\text { cama } \\
\text { carro } \\
\text { chapéu } \\
\text { chave } \\
\text { chuveiro } \\
\text { escova } \\
\text { escova de dente } \\
\text { estrela } \\
\text { flor } \\
\text { garrafa } \\
\text { geladeira }\end{array}$ & $\begin{array}{l}\text { guarda-chuva } \\
\text { janela } \\
\text { livro } \\
\text { mesa } \\
\text { óculos } \\
\text { passarinho } \\
\text { pente } \\
\text { quadro } \\
\text { relógio } \\
\text { sol } \\
\text { telefone } \\
\text { televisão } \\
\text { vaso } \\
\text { vassoura } \\
\text { vestido }\end{array}$ & $\begin{array}{l}\text { mão (macro-) } \\
\text { olho (macro-) } \\
\text { orelha (macro-) }\end{array}$ \\
\hline
\end{tabular}


v. 11 (esp.)

$120-142$

ago.

2021

\begin{tabular}{|c|ll|l|}
\hline $\begin{array}{c}\text { Referente incluído sem } \\
\text { ilustração no dicionário. } \\
4 / 79(5 \%)\end{array}$ & $\begin{array}{l}\text { banco } \\
\text { botão }\end{array}$ & $\begin{array}{l}\text { caneta } \\
\text { cinto }\end{array}$ & --- \\
\hline $\begin{array}{c}\text { Referente ausente do } \\
\text { dicionário }\end{array}$ & $\begin{array}{l}\text { abajur } \\
\text { batom } \\
\text { cabide } \\
\text { cadeado } \\
\text { colete }\end{array}$ & $\begin{array}{l}\text { copo } \\
\text { ferro } \\
\text { guarda-roupa } \\
\text { martelo } \\
\text { panela }\end{array}$ & $\begin{array}{l}\text { pneu } \\
\text { pregador } \\
\text { roda-gigante }\end{array}$ \\
\hline
\end{tabular}

Fonte: elaboração da autora a partir do cruzamento dos dados do Anexo 1 com os do MPCA (2009).

Diferentemente do anterior, o MPCA (2009) registra a maior parte dos referentes na macroestrutura. O dicionário também se destaca em relação aos outros dois por quase sempre incluir uma ilustração junto dos verbetes relativos aos referentes analisados. No caso das partes do corpo, todas estavam incluídas na macroestrutura sem ilustração e continham uma remissão ao back matter onde há um diagrama elucidativo do corpo humano ("Corpo humano", p. 202). Fica evidente para o consulente que, caso sua dúvida esteja relacionada a esse campo léxico, encontrará informações no back matter.

Um fator que se destacou durante a análise foi a considerável proporção de ilustrações não elucidativas, parelhada à proporção das ilustrações elucidativas. O fator que mais interferiu para que a classificação fosse negativa para $43 \%$ das ilustrações foi a participação de outros elementos ilustrados junto do referente e que interferem na identificação deste. Muitos deles são personagens fictícios da série "Turma do Cocoricó", que é o chamariz do dicionário para atrair a atenção do consulente almejado. Sobre este particular, o próprio PNLD Dicionários (BRASIL, 2012, p. 28) reconhece que o universo imaginário que serve de base para a ilustração dos verbetes nem sempre fornecerá imagens claras daquilo que almeja representar. Porém, diminuir o grau elucidativo de uma ilustração para dar ênfase a uma personagem torna o dicionário um livro para se folhear e ver imagens bonitas, não para tirar dúvidas.

Foi possível identificar três tipos de ilustrações não elucidativas: a) ilustração na qual há um personagem interagindo com o referente, seja vestindo-o (roupas e acessórios), manuseando-o (objetos) ou outro tipo de interação ${ }^{6}$; b) ilustração na qual há um personagem em primeiro plano ou com mais destaque, enquanto o referente principal

\footnotetext{
${ }^{6}$ Casos de personagens interagindo com o referente: s.vs. bicicleta, bolsa, boné, cachorro, cama, carro, chapéu, chuveiro, escova (de cabelo, de dentes), flor, garrafa, geladeira, guarda-chuva, janela, livro, mesa, óculos, pente, quadro, vassoura, vestido. Observação: lê-se s.v. como no verbete.
} 
está em segundo plano ou recebe menos destaque7; c) ilustração na qual há outros referentes presentes para demonstrar a função do referente principal $^{8}$. Ao apresentarem personagens interagindo com o referente ou ao usar outros objetos para demonstrar a função do referente, algumas ilustrações tiram o foco do referente e abarcam uma ação, remetendo a verbos ao invés de substantivos. Por exemplo: no verbete cachorro, a ilustração contém uma personagem brincando com o referente. Nesse caso, a ilustração reflete muito mais o verbo brincar que o substantivo cachorro. Outro exemplo: no verbete chave, aparecem tanto chaves isoladas como baús para demonstrar que as chaves abrem dispositivos como este. Nos casos de peças de roupa, a participação da personagem termina desviando totalmente o foco do referente. No verbete vestido, por exemplo, há uma personagem usando tal vestimenta, o que não permite identificar o alvo da ilustração.

Finalmente, as ilustrações nos verbetes telefone e televisão padecem do mesmo problema verificado no MPLP (2010), ou seja, são de modelos não mais comercializados (telefone de disco e televisão de tubo). Em mão, olho e orelha, desenha-se o busto de um personagem, em vez de ilustrar apenas o referente.

Análise do DInf (2011)

O Quadro 5 contém os resultados da análise do DInf (2011):

Quadro 5 - Análise de referentes e ilustrações no DInf (2011)

\begin{tabular}{|c|c|c|c|}
\hline \multirow{2}{*}{$\begin{array}{c}\text { Inclusão do referente no } \\
\text { dicionário }\end{array}$} & \multicolumn{3}{|c|}{ Localização do referente } \\
\hline & \multicolumn{2}{|c|}{ Macroestrutura } & Back matter \\
\hline $\begin{array}{l}\text { Referente incluído e } \\
\text { ilustrado no dicionário. } \\
\begin{array}{c}\text { A ilustração é } \\
\text { elucidativa. } \\
29 / 79(36,7 \%)\end{array}\end{array}$ & $\begin{array}{l}\text { abajur } \\
\text { árvore } \\
\text { bolsa } \\
\text { caminhão } \\
\text { carro } \\
\text { casa } \\
\text { chave } \\
\text { cinto } \\
\text { escada }\end{array}$ & $\begin{array}{l}\text { garrafa } \\
\text { guarda-roupa } \\
\text { janela } \\
\text { lâmpada } \\
\text { ônibus } \\
\text { tesoura } \\
\text { vassoura } \\
\text { xícara }\end{array}$ & $\begin{array}{l}\text { abelha (p.122) } \\
\text { banana (p.125) } \\
\text { braço (p.120) } \\
\text { cachorro (p.122) } \\
\text { dedo (p.120) } \\
\text { gato (p.123) } \\
\text { maçã (p.125) } \\
\text { mão (p.120) } \\
\text { nariz (p.120) } \\
\text { olho (p.120) } \\
\text { orelha (p.120) } \\
\text { tomate (p.127) }\end{array}$ \\
\hline
\end{tabular}

\footnotetext{
${ }^{7}$ Casos de personagens com mais destaque que o referente: s.vs. estrela, passarinho, sol.

${ }^{8}$ Casos de foco na função do referente: s.vs. anel, chave, relógio, vaso.
} 
v. 11 (esp.)

$120-142$ ago. 2021

\begin{tabular}{|c|c|c|c|}
\hline $\begin{array}{l}\text { Referente incluído e } \\
\text { ilustrado no dicionário. } \\
\begin{array}{c}\text { A ilustração não é } \\
\text { elucidativa. }\end{array} \\
11 / 79(13,9 \%)\end{array}$ & $\begin{array}{l}\text { bicicleta } \\
\text { blusa } \\
\text { calça } \\
\text { caneta } \\
\text { chapéu } \\
\text { chuveiro }\end{array}$ & $\begin{array}{l}\text { copo } \\
\text { guarda-chuva } \\
\text { livro } \\
\text { óculos } \\
\text { sol }\end{array}$ & --- \\
\hline $\begin{array}{l}\text { Referente incluído sem } \\
\text { ilustração no dicionário. } \\
\qquad 21 / 79(26,5 \%)\end{array}$ & $\begin{array}{l}\text { banco } \\
\text { boné } \\
\text { cadeira } \\
\text { cama } \\
\text { colher } \\
\text { escova } \\
\text { estrela } \\
\text { flor } \\
\text { garfo } \\
\text { geladeira } \\
\text { mesa } \\
\end{array}$ & $\begin{array}{l}\text { panela } \\
\text { pão } \\
\text { pássaro } \\
\text { pente } \\
\text { quadro } \\
\text { relógio } \\
\text { sapato } \\
\text { telefone } \\
\text { televisão } \\
\text { vestido }\end{array}$ & --- \\
\hline $\begin{array}{c}\begin{array}{c}\text { Referente ausente do } \\
\text { dicionário }\end{array} \\
18 / 79(22,7 \%)\end{array}$ & $\begin{array}{l}\text { agulha } \\
\text { anel } \\
\text { batom } \\
\text { botão } \\
\text { cabide } \\
\text { cadeado }\end{array}$ & $\begin{array}{l}\text { colete } \\
\text { escova de dente } \\
\text { ferro } \\
\text { fogão } \\
\text { formiga } \\
\text { martelo }\end{array}$ & $\begin{array}{l}\text { pneu } \\
\text { pote } \\
\text { pregador } \\
\text { roda-gigante } \\
\text { sanduíche } \\
\text { vaso }\end{array}$ \\
\hline
\end{tabular}

Fonte: elaboração da autora a partir do cruzamento dos dados do Anexo $1 \mathrm{com}$ os do DInf (2011).

A maior parte dos referentes incluídos no dicionário se encontra na macroestrutura. Partes do corpo, animais e frutas estão incluídos somente no back matter, em diagramas ilustrados.

Somando-se as categorias de ilustrações não elucidativas e de referentes não ilustrados, obtém-se um índice similar ao de ilustrações elucidativas. Esse dado permite constatar que as ilustrações poderiam ser mais bem exploradas para facilitar a associação entre um referente e a sua representação ortográfica.

As ilustrações não elucidativas apresentam dois problemas comentados na análise do MPCA (2009), quais sejam, personagens interagindo com o referente ${ }^{9}$ e foco na função do referente ${ }^{10}$. Nesses casos, assim como na análise do MPCA (2010), é de se questionar se as informações sobre os tipos de interação com um referente e a sua função correspondem às principais necessidades de crianças em fase de alfabetização.

\footnotetext{
${ }^{9}$ É o caso das ilustrações s.vs. bicicleta, blusa, calça, chapéu, chuveiro, guarda-chuva, livro e óculos.

${ }^{10}$ É o caso das ilustrações s.vs. caneta, copo e sol.
} 


\section{Considerações finais}

Muitas ilustrações foram incluídas no MPLP (2010), no MPCA (2009) e no DInf (2011) como chamariz para compra e consulta às obras, sem que se refletisse sobre a funcionalidade desse recurso explanatório frente às necessidades linguísticas do usuário almejado. A partir dos documentos oficiais sobre alfabetização, depreende-se que crianças nessa fase escolar inicial precisam de um dicionário que as auxilie a comprovar ou a refutar hipóteses ortográficas. O mecanismo explanatório que melhor pode auxiliar nessa tarefa são as ilustrações. Como a leitura das palavras-entrada consiste já um desafio atrelado ao propósito da consulta, a função das ilustrações é a de auxiliar na localização de referentes suscitando um processo de familiaridade, tornando-as mais importantes e úteis para o usuário de dicionários Tipo 1 do que as paráfrases explanatórias. Quando a ilustração não é elucidativa, a esperada familiaridade com o referente não acontece, tornando-a ineficaz sob o ponto de vista metalexicográfico. Por outro lado, na ausência de ilustração junto a designações cuja representação ortográfica é desafiadora para um alfabetizando, há um subaproveitamento desse recurso. Frente a esses resultados, espera-se que os critérios de avaliação empregados neste artigo possam contribuir também na compilação de dicionários que almejam auxiliar alfabetizandos.

Outra questão a ser investigada é se um dicionário semasiológico, que ampara a localização de informações no conhecimento prévio da progressão alfabética, seria a melhor opção para o usuário. É de se questionar se diagramas temáticos, tais como os encontrados no back matter das obras analisadas, não seriam uma solução mais adequada para alfabetizandos.

Agradecimentos: À profa. Dra. Ana Fontes, em cujas aulas surgiu o esboço da pesquisa, e ao prof. Dr. Félix Miranda, por incentivar a busca pela interdisciplinaridade. Dedico o artigo a minha mãe, Marília T. Campos.

\section{Referências}

ANTONIOLI, J. Considerações sobre dicionários escolares destinados a alfabetizandos. 2012. 136 f. Dissertação (Mestrado em Teorias Linguísticas do Léxico) - Instituto de Letras, Universidade Federal do Rio Grande do Sul, Porto Alegre, 2012. Disponível em: hdl.handle.net/10183/172395. Acesso em: 6 ago. 2020. 
v. 11 (esp.)

$120-142$ ago. 2021

BOGAARDS, P. Uses and users of dictionaries. In: STERKENBURG, P. (Org.). A Practical Guide to Lexicography. Amsterdam: John Benjamins, 2003. cap. 1.3, p. $26-33$.

BORBA, L. C. Princípios de uma fundamentação teórica para a inclusão de ilustrações em dicionários infantis à luz da Psicologia Cognitiva. In: XIII Semana de Extensão, Pesquisa e Pós-Graduação UNIRITTER (SEPesq), 2017, Porto Alegre. Atas da XIII SEPesq UNIRITTER. Porto Alegre: Uniritter, 2018. p. 1-12. Disponível em: www.uniritter.edu.br/xiii-sepesq. Acesso em: 28 ago. 2020.

BORBA, L. C.; BUGUEÑO MIRANDA, F. V. Passado, presente e futuro dos dicionários de aprendizes. Domínios de Lingu@agem, Uberlândia, v. 13 n. 3, p. 1018-1040, 2019. Disponível em: doi.org/10.14393/DL39-v13n3a2019-9. Acesso em: 8 jun. 2020.

BRASIL. MINISTÉRIO DA EDUCAÇÃO. SECRETARIA DE EDUCAÇÃO BÁSICA. Com direito à palavra: dicionários em sala de aula. Elaboração de Egon de Oliveira Rangel. Brasília: Ministério da Educação; Secretaria de Educação Básica, 2012. Disponível em: http://portal.mec.gov.br/index.php?option=com docman\&view=download\&alias =12059-dicionario-em-sala-de-aula-pnldpdf\&Itemid=30192. Acesso em: 28 ago. 2020.

BRASIL. MINISTÉRIO DA EDUCAÇ̃̃O. SECRETARIA DE EDUCAÇÃO BÁSICA. Livros selecionados PNBE 2013. Brasília: Ministério da Educação; Secretaria da Educação Básica, 2013.

BRASIL. MINISTÉRIO DA EDUCAÇÃO. SECRETARIA DE EDUCAÇÃO BÁSICA. Base Nacional Comum Curricular. Brasília: Ministério da Educação; Secretaria da Educação Básica, 2018. Disponível em: http://basenacionalcomum.mec. gov.br/. Acesso em: 28 ago. 2020.

BUGUEÑO MIRANDA, F. Para uma taxonomia de paráfrases explanatórias. Alfa, São Paulo, v. 53, n. 1, p. 243-260, 2009. Disponível em: periodicos.fclar. unesp.br/alfa/article/view/1686. Acesso em: 06 ago. 2020.

BUGUEÑO MIRANDA, F. Sobre a classificação de obras lexicográficas. In: BUGUEÑO MIRANDA, F.; BORBA, L. C. (orgs.). Manual de (Meta)Lexicografia. Goiânia: Editora Espaço Acadêmico, 2019. Cap. 4, p. 30-36. Disponível em: www.ufrgs.br/metalexicografia/manual-de-meta-lexicografia. Acesso em: 14 mai. 2020.

\section{CAGLIARI, L. Alfabetização e Lingüística. São Paulo: Scipione, 2003.}

CREESE, S. et al. Everything You Always Wanted to Know about Dictionaries (But Were Afraid to Ask): A Massive Open Online Course. In: ČIBEJ, J.; GORJANC, V.; KOSEM, I.; KREK, S. (Orgs.). In: XVIII EURALEX International Congress, Ljubljana, 2018. Proceedings of the XVIII EURALEX International Congress, Ljubljana: Ljubljana University Press, 2018, p. 59-66. Disponível em: euralex.org/publications/everything-you-always-wanted-to-knowaboutdictionaries-but-were-afraid-to-ask-a-massive-open-online-course/. Acesso em: 6 ago. 2020.

DInf. BECHARA, E. Dicionário infantil ilustrado Evanildo Bechara. Ilustrações de Thais Linhares. Rio de Janeiro: Nova Fronteira, 2011. 
FARIAS, V. S. Sobre a definição lexicográfica e seus problemas. Fundamentos para uma teoria geral dos mecanismos explanatórios em dicionários semasiológicos. 2013. 398 f. Tese (Doutorado em Teorias Linguísticas do Léxico) - Instituto de Letras, Universidade Federal do Rio Grande do Sul, Porto Alegre, 2013. Disponível em: hdl.handle.net/10183/90167. Acesso em: 6 ago. 2020.

KLOTZ, M.; HERBST, T. English Dictionaries. A Linguistic Introduction. Berlin: Erich Schmidt Verlag, 2016.

MPCA. GEIGER, P. (ed.). Meu primeiro dicionário: Caldas Aulete com a turma do Cocoricó. Vários ilustradores. São Paulo: Globo; Rio de Janeiro: Lexikon, 2009.

MPLP. BIDERMAN, M. T. C.; CARVALHO, C. S. Meu primeiro livro de palavras. Um dicionário ilustrado do português de A a Z. $2^{\mathrm{a}}$ ed. Ilustrações de Orlando Pedroso. São Paulo: Ática, 2010.

NASCIMENTO, F. Lexicografia Multimodal: como as crianças percebem os recursos visuais dos dicionários infantis. Discursividades, Campina Grande, v. 3, n. 2, p. 87-103, 2018. Disponível em: revista.uepb.edu.br/index.php/ REDISC/article/view/4951. Acesso em: 6 ago. 2020.

NESI, H. Dictionary Use. In: CHAPELLE, Carol A. (Org.). The Encyclopedia of Applied Linguistics. Oxford: Wiley-Blackwell, 2013. p. 1-5.

PESSOA, A. C.; MORAIS, A. Relações entre habilidades metafonológicas, explicitação verbal e desempenho ortográfico. Cadernos de Educação, Pelotas, v. 35, p. 109-138, 2010. Disponível em: dx.doi.org/10.15210/caduc.voi35.1617. Acesso em: 6 ago. 2020.

POMPÉIA, S.; MIRANDA, M. C.; BUENO, O. F. A set of 400 pictures standardised for Portuguese. Norms for name agreement, familiarity and visual complexity for children and adults. Arquivos de Neuro-Psiquiatria, São Paulo, v. 59, n. 2B, p. 330-337, 2001. Disponível em: www.scielo.br/pdf/anp/v59n2B/ a04V592b.pdf. Acesso em: 6 ago. 2020.

PONTES, A. L. O verbal e o não-verbal em dicionários didáticos: um enfoque multimodal. In: ARAÚJO, J. C.; BIASE-RODRIGUES, B.; DIEB, M. (org.). Seminários linguísticos: discurso, análise linguística, ensino e pesquisa. Mossoró: Edições UERN, 2010 a.

PONTES, A. L. Multimodalidade em dicionários escolares. In: ISQUERDO, A. N.; BARROS, L. A. (org.). As ciências do léxico: Lexicologia, Lexicografia, Terminologia. Mato Grosso do Sul: UFMS, $2010 b$.

PONTES, A. L. Articulação verbo-visual em verbetes lexicográficos de dicionários escolares brasileiros. In: PONTES, A. L. et al. (orgs.). Perspectivas em Lexicografia e terminologia. Fortaleza: EdUECE, 2018. cap. 1, p. 16-50. Disponível em: portal-archipelagus.azurewebsites.net/farol/eduece/ebook/ perspectivas-em-lexicografia-e-terminologia/525727/. Acesso em: 28 ago. 2020.

RUNDELL, M. Recent Trends in English Pedagogical Lexicography. In: FONTENELLE, T. Practical Lexicography: a reader. New York: Oxford University Press, 2008. cap. 16, p. 221-243. 
v. 11 (esp.)

$120-142$ ago. 2021
SANTOS, T. M. R. Estudo da relação verbo-visual no dicionário Aurelinho. In: PONTES, A. L. et al. (orgs.). Perspectivas em Lexicografia e terminologia. Fortaleza: EdUECE, 2018. cap. 1, p. 287-301. Disponível em: portal-archipelagus. azurewebsites.net/farol/eduece/ebook/perspectivas-em-lexicografia-eterminologia/525727/. Acesso em: 28 ago. 2020.

SANTOS, T. M. R.; CORIOLANO, R. R.; PONTES, A. L. O uso de fotografias em verbetes de dicionários infantis. Leitura, Maceió, n. 63, p. 138-153, 2019. Disponível em: 10.28998/2317-9945.2019n63p138-153. Acesso em: 28 ago. 2020.

YONELINAS, A. The nature of recollection and familiarity: a review of 30 years of research. Journal of Memory and Language, [s.l.], v. 46, n. 3, p. 441517, 2002. Disponível em: doi.org/10.1006/jmla.2002.2864. Acesso em: 6 ago. 2020. 


\section{Anexo 1}

Instrumento de avaliação de ilustrações em dicionários infantis Tipo 1 (versão revisada)

\begin{tabular}{|c|c|c|c|c|c|c|c|c|c|c|c|c|}
\hline \multirow{2}{*}{ Unidade léxica } & \multicolumn{12}{|c|}{ DIFICULDADES ORTOGRÁFICAS NA ALFABETIZAÇÃO } \\
\hline & NEUTR & DITON & MONOT & APAG & $*_{\mathrm{U}(\mathrm{L})}$ & $*_{\mathrm{LI}(\mathrm{LH})}$ & $/ \mathrm{J} /$ & $|s|$ & $|3|$ & NASAL & $\mid \mathrm{x} /$ & $|z|$ \\
\hline abajur & & & & & & & & & $\mathrm{X}$ & & & \\
\hline abelha & & & & & & $\mathrm{X}$ & & & & & & \\
\hline agulha & & & & & & $\mathrm{X}$ & & & & & & \\
\hline anel & & & & & $\mathrm{X}$ & & & & & & & \\
\hline árvore & $\mathrm{X}$ & & & & & & & & & & & \\
\hline banana & & & & & & & & & & $\mathrm{X}$ & & \\
\hline banco & $\mathrm{X}$ & & & & & & & & & $\mathrm{X}$ & & \\
\hline batom & & & & & & & & & & $\mathrm{X}$ & & \\
\hline bicicleta & & & & & & & & $\mathrm{X}$ & & & & \\
\hline blusa & & & & & & & & & & & & $\mathrm{X}$ \\
\hline bolsa & & & & & $\mathrm{X}$ & & & $\mathrm{X}$ & & & & \\
\hline boné & $\mathrm{X}$ & & & & & & & & & & & \\
\hline botão & $\mathrm{X}$ & & & & & & & & & $\mathrm{X}$ & & \\
\hline braço & $\mathrm{X}$ & & & & & & & $\mathrm{X}$ & & & & \\
\hline cabide & $\mathrm{X}$ & & & & & & & & & & & \\
\hline cachorro & $\mathrm{X}$ & & & & & & $\mathrm{X}$ & & & & $\mathrm{X}$ & \\
\hline cadeado & $\mathrm{X}$ & & & & & & & & & & & \\
\hline cadeira & & & $\mathrm{X}$ & & & & & & & & & \\
\hline calça & & & & & $\mathrm{X}$ & & & $\mathrm{X}$ & & & & \\
\hline cama & & & & & & & & & & $X$ & & \\
\hline caminhão & & & & & & & & & & $\mathrm{X}$ & & \\
\hline caneta & & & & & & & & & & $\mathrm{X}$ & & \\
\hline carro & $\mathrm{X}$ & & & & & & & & & & $\mathrm{X}$ & \\
\hline casa & & & & & & & & & & & & $\mathrm{X}$ \\
\hline chapéu & & & & & & & $\mathrm{X}$ & & & & & \\
\hline chave & $\mathrm{X}$ & & & & & & $\mathrm{X}$ & & & & & \\
\hline chuveiro & $\mathrm{X}$ & & $\mathrm{X}$ & & & & $\mathrm{X}$ & & & & & \\
\hline cinto & $\mathrm{X}$ & & & & & & & $\mathrm{X}$ & & & & \\
\hline colete & $\mathrm{X}$ & & & & & & & & & & & \\
\hline colher & $\mathrm{X}$ & & & $\mathrm{X}$ & & & & & & & & \\
\hline copo & $\mathrm{X}$ & & & & & & & & & & & \\
\hline dedo & $\mathrm{X}$ & & & & & & & & & & & \\
\hline escada & $\mathrm{X}$ & & & & & & & & & & & \\
\hline escova & $\mathrm{X}$ & & & & & & & & & & & \\
\hline $\begin{array}{c}\text { escova de } \\
\text { dente }\end{array}$ & $\mathrm{X}$ & & & & & & & & & $\mathrm{X}$ & & \\
\hline estrela & $\mathrm{X}$ & & & & & & & & & & & \\
\hline ferro & $\mathrm{X}$ & & & & & & & & & & $\mathrm{X}$ & \\
\hline flor & & & & X & & & & & & & & \\
\hline fogão & $\mathrm{X}$ & & & & & & & & & $\mathrm{X}$ & & \\
\hline
\end{tabular}


v. 11 (esp.) $120-142$ ago. 2021

\begin{tabular}{|c|c|c|c|c|c|c|c|c|c|c|c|}
\hline formiga & $\mathrm{X}$ & & & & & & & & & & \\
\hline garfo & $\mathrm{X}$ & & & & & & & & & & \\
\hline garrafa & & & & & & & & & & $\mathrm{X}$ & \\
\hline gato & $\mathrm{X}$ & & & & & & & & & & \\
\hline geladeira & & $\mathrm{X}$ & & & & & & $\mathrm{X}$ & & & \\
\hline guarda-chuva & & & & & & $\mathrm{X}$ & & & & & \\
\hline guarda-roupa & & $\mathrm{X}$ & & & & & & & & & \\
\hline janela & & & & & & & & $\mathrm{X}$ & & & \\
\hline lâmpada & & & & & & & & & $\mathrm{X}$ & & \\
\hline livro & $\mathrm{X}$ & & & & & & & & & & \\
\hline maçã & & & & & & & $\mathrm{X}$ & & $\mathrm{X}$ & & \\
\hline mão & & & & & & & & & $\mathrm{X}$ & & \\
\hline martelo & $\mathrm{X}$ & & & & & & & & & & \\
\hline mesa & & & & & & & & & & & $\mathrm{X}$ \\
\hline nariz & & & & & & & $\mathrm{X}$ & & & & \\
\hline óculos & $\mathrm{X}$ & & & & & & & & & & \\
\hline olho & $\mathrm{X}$ & & & & $\mathrm{X}$ & & & & & & \\
\hline ônibus & & & & & & & & & $\mathrm{X}$ & & \\
\hline orelha & & & & & $\mathrm{X}$ & & & & & & \\
\hline panela & & & & & & & & & $\mathrm{X}$ & & \\
\hline pão & & & & & & & & & $\mathrm{X}$ & & \\
\hline passarinho & & & & & & & $\mathrm{X}$ & & $\mathrm{X}$ & & \\
\hline pente & $\mathrm{X}$ & & & & & & & & $\mathrm{X}$ & & \\
\hline pneu & & & & & & & & & $\mathrm{X}$ & & \\
\hline pote & $\mathrm{X}$ & & & & & & & & & & \\
\hline pregador & & & $\mathrm{X}$ & & & & & & & & \\
\hline quadro & $\mathrm{X}$ & & & & & & & & & & \\
\hline relógio & $\mathrm{X}$ & $\mathrm{X}$ & & & & & & $\mathrm{X}$ & & $\mathrm{X}$ & \\
\hline roda-gigante & $\mathrm{X}$ & & & & & & & $X$ & & & \\
\hline sanduíche & $\mathrm{X}$ & & & & & $\mathrm{X}$ & & & $\mathrm{X}$ & & \\
\hline sapato & $\mathrm{X}$ & & & & & & & & & & \\
\hline sol & & & & $\mathrm{X}$ & & & & & & & \\
\hline telefone & $\mathrm{X}$ & & & & & & & & & & \\
\hline televisão & & & & & & & & & $\mathrm{X}$ & & $\mathrm{X}$ \\
\hline tesoura & $\mathrm{X}$ & $\mathrm{X}$ & & & & & & & & & $\mathrm{X}$ \\
\hline tomate & $\mathrm{X}$ & & & & & & & & & & \\
\hline vaso & $\mathrm{X}$ & & & & & & & & & & $\mathrm{X}$ \\
\hline vassoura & & $\mathrm{X}$ & & & & & $\mathrm{X}$ & & & & \\
\hline vestido & $\mathrm{X}$ & & & & & & & & & & \\
\hline xícara & & & & & & $\mathrm{X}$ & & & & & \\
\hline
\end{tabular}

Fonte: versão revisada da proposta de Borba (2018, p. 9-11)

Nota: banco se refere ao móvel para sentar-se; botão se refere à peça usada no vestuário; colher se refere ao tipo de talher; ferro se refere ao eletrodoméstico para passar roupas; pregador se refere ao objeto para fixar roupas em um varal; quadro se refere ao objeto de decoração pendurado na parede; vaso se refere ao recipiente para abrigar plantas ou ornamentar ambientes. 